\title{
Obesity, perceived weight discrimination, and hair cortisol: a population- based study
}

\author{
Sarah E. Jackson ${ }^{1}$, Andrew Steptoe ${ }^{1}$ \\ ${ }^{1}$ Department of Behavioural Science and Health, University College London, London, UK
}

Running head: Obesity, weight discrimination and cortisol

Word count: 2687

Number of figures and tables: 3

Declarations of interest: none.

Corresponding author: Sarah E Jackson, PhD. Department of Behavioural Science and Health, University College London, 1-19 Torrington Place, London WC1E 6BT

Tel: (44) 2076795616

Fax: (44) 2079168354

s.e.jackson@ucl.ac.uk 


\begin{abstract}
Background and purpose: Stigmatization of individuals with obesity is pervasive and may act as a psychological stressor. The present study examined whether perceived weight discrimination mediated the relationship between obesity and cortisol, an objective marker of chronic stress, in a population-based sample.
\end{abstract}

Methods: Data were from the English Longitudinal Study of Ageing $(n=1872)$. Height and weight were objectively measured in 2008/09. Experiences of weight-related discrimination were reported via questionnaire in $2010 / 11$. Hair cortisol concentrations were determined from the scalp-nearest $2 \mathrm{~cm}$ hair segment in 2012/13. Mediation analyses tested the role of perceived weight discrimination in the associations between obesity and BMI and hair cortisol concentration, adjusting for age, sex, ethnicity, socio-economic status, smoking status, depression and hair-related factors.

Results: Obesity, BMI and perceived weight discrimination were positively related to hair cortisol (all $p<$ .01). Perceived weight discrimination significantly mediated associations between obesity and hair cortisol $(\beta=0.021, \mathrm{SE}=0.007,95 \% \mathrm{Cl} 0.007-0.036)$ and $\mathrm{BMI}$ and hair cortisol $(\beta=0.001, \mathrm{SE}=0.0004,95 \% \mathrm{Cl}$ $0.0004-0.002$ ), accounting for $19 \%$ of the total effect of obesity and $23 \%$ of the total effect of BMI on hair cortisol.

Conclusions: Perceived weight discrimination is an important mediator of the association between obesity and cortisol. Interventions combating weight stigma and discrimination or promoting strategies for coping with stress could help to lessen the psychological and physiological burden of obesity.

Key words: Obesity; Weight-related discrimination; Stigma; Stress; Cortisol 


\section{Introduction}

Obesity is recognized as a global health issue, and associations with a wide range of adverse psychological and physiological correlates have long been established (Ng et al., 2014). Recent years have seen a growing interest in the relationship between obesity and stress, with symptoms of metabolic syndrome - a cluster of comorbidities that often accompany obesity - closely mirroring those of Cushing's syndrome, a disorder caused by overproduction of the stress hormone cortisol (Anagnostis et al., 2009). Chronic stress has been posited to play a role in the development of obesity through effects of cortisol on body composition and eating behavior (Björntorp, 2001; Dallman et al., 2003; Pervanidou and Chrousos, 2011; Torres and Nowson, 2007), and several studies have reported chronically elevated cortisol concentrations in individuals living with obesity (Manenschijn et al., 2011b; Veldhorst et al., 2013; Wester et al., 2014).

While the existing literature on cortisol and adiposity has predominantly focused on an etiological role of stress in obesity, there may be a bidirectional aspect to the relationship, with weight stigma playing an important role as a chronic stressor. A large body of research has demonstrated a clear relationship between obesity and weight stigma, with stigmatizing and discriminatory experiences increasing with the severity of obesity (see (Puhl and Brownell, 2001; Puhl and Heuer, 2009) for reviews). In population surveys, up to $14 \%$ of individuals with moderate obesity (body mass index [BMI] $30-34.9 \mathrm{~kg} / \mathrm{m}^{2}$ ) and $43 \%$ with severe obesity $\left(\mathrm{BMI} \geq 35 \mathrm{~kg} / \mathrm{m}^{2}\right.$ ) report being mistreated because of their weight (Andreyeva et al., 2008; Jackson et al., 2015b), but studies using daily diaries to document experiences of weight stigma suggest discriminatory experiences may be more common than this, with the average participant reporting 0.79-3.08 stigmatizing events every day (Seacat et al., 2014; Vartanian et al., 2014).

There has been rather less research into the impact of weight stigma on stress. A large population survey in the US found a strong association between perceived weight discrimination and self-reported stress, with overweight and obese individuals reporting weight-related discrimination being more than 3 times more 
likely to be in the highest quartile of perceived stress than those who had not experienced weight discrimination (Hatzenbuehler et al., 2009). Associations with physiological markers of stress have also been documented: two recent experimental studies observed increased cortisol reactivity in response to exposure to weight stigma (Himmelstein et al., 2015; Schvey et al., 2014). Considering how frequently people experience weight stigma (Puhl and Brownell, 2006), multiple reactivity spikes could contribute to chronically elevated cortisol. Observational studies have reported elevated cortisol levels in individuals who have experienced weight stigma and discrimination (Jackson et al., 2016; Tomiyama et al., 2014).

The indirect effect of obesity on stress via weight stigma has yet to be empirically tested. The present study was therefore designed to examine the role of weight discrimination as a mediator of the relationship between obesity and stress. It used data from the English Longitudinal Study of Ageing (ELSA), a large population-based study with assays of cortisol in scalp hair as a marker of chronic biochemical stress. This method for assessing cortisol has advantages over traditional measures using saliva, urine or serum, because it is not vulnerable to daily fluctuations and reflects average exposure to cortisol over approximately one month per $1 \mathrm{~cm}$ of scalp-proximal hair (Stalder and Kirschbaum, 2012). Previous studies in the ELSA cohort and other samples have documented a positive association between obesity and hair cortisol (Jackson et al., 2017; Manenschijn et al., 2011b; Noppe et al., 2016; Veldhorst et al., 2013; Wester et al., 2014), but this literature needs further development and the mechanisms underlying this association are not well understood. Relationships between perceived weight discrimination and both obesity (Jackson et al., 2015b) and hair cortisol (Jackson et al., 2016) have also been observed in ELSA, but the potential mediating role of weight discrimination has not been tested in this or any other sample. This study tested the hypothesis that a substantial proportion of the observed association between obesity and chronic stress would be explained by perceptions of weight discrimination. 


\section{Method}

\section{Study population}

ELSA is a longitudinal, nationally-representative panel study of men and women aged 50 and older living in England (Steptoe et al., 2013). Established in 2002, ELSA collects data via computer-assisted personal interviews and self-completion questionnaires every two years, with nurse visits in alternate (even) waves to collect objective measures of health status, including height and weight. Full details of ELSA's data collection methods are described at http://www.elsa-project.ac.uk. Seven waves of data have been collected to date. Wave $6(2012 / 13)$ was the first assessment that included the collection of hair samples for cortisol analysis. In the present study, these data are used in conjunction with anthropometric information gathered in Wave 4 and self-reported data on perceived discrimination collected in Wave 5 (2010/11; the only wave in which discrimination has been assessed). Complete data on cortisol, BMI and perceived weight discrimination were available for 1,872 men and women, who comprised the final analytic sample. The study was approved by the National Research Ethics Service, and all participants provided informed signed consent.

\section{Measures}

Obesity was defined as a $\mathrm{BMI} \geq 30 \mathrm{~kg} / \mathrm{m}^{2}$, calculated from objective measures of weight and height. Weight was measured by nurses to the nearest $0.1 \mathrm{~kg}$ using portable electronic scales, and height was measured to the nearest millimeter using a portable stadiometer. Nurses recorded any factors that might have compromised the reliability of the measurements (e.g., participant was stooped or unwilling to remove their shoes) and these cases were excluded. The decision to use obese vs. non-obese, rather than overweight/obese vs. normal-weight as the independent variable was based on results of previous analyses in this cohort indicating very low prevalence of perceived weight discrimination among overweight 
respondents, with levels of reported discrimination in the overweight group more comparable to normalweight than obese respondents (Jackson et al., 2015b).

Perceived weight discrimination was self-reported in response to the question: "In your day-to-day life, how often have any of the following things happened to you: (1) you are treated with less respect or courtesy; (2) you receive poorer service than other people in restaurants and stores; (3) people act as if they think you are not clever; (4) you are threatened or harassed; and (5) you receive poorer service or treatment than other people from doctors or hospitals". Response options were "never", "less than once a year", "a few times a year", "a few times a month", "at least once a week" and "almost every day". Data were highly skewed, with the majority of respondents reporting never experiencing discrimination, so for the present analyses responses were dichotomized to indicate whether or not respondents regularly experienced discrimination in any domain (never/less than once a year vs. a few times a year or more). Participants who reported experiences of discrimination in any of the domains were asked the reason(s) they attributed these to from a list of options including age, sex, race, and weight. Those who attributed any regular experience of discrimination to their weight are treated in this study as cases of perceived weight discrimination. This measure has previously been used to evaluate the prevalence of weight discrimination and associations with weight change and measures of psychological and physiological health in this cohort (Jackson et al., 2014, 2015a, 2015b, 2016).

Hair samples were collected from all consenting participants for analysis of cortisol. Scalp-proximal samples measuring at least $2 \mathrm{~cm}$ in length and weighing at least $10 \mathrm{mg}$ were collected from the posterior vertex. Exclusion criteria for hair sampling included pregnancy, breastfeeding, certain scalp conditions, inability to sit with head remaining still, or hair length less than $2 \mathrm{~cm}$ in the posterior vertex scalp area. The full hair sampling procedure is described at http://www.elsaproject.ac.uk/uploads/elsa/docs_w6/project_instructions_nurse.pdf. The wash procedure and steroid 
extraction were undertaken using high performance liquid chromatography-mass spectrometry (LC/MS), as described by Gao et al. (2013). Based on hair growth of around $1 \mathrm{~cm}$ per month (Kintz et al., 2006), samples from the $2 \mathrm{~cm}$ of hair closest to the scalp reflect average cortisol exposure over an approximate timespan of two months prior to sampling, with higher cortisol levels indicating greater levels of stress. Considerable evidence supports the validity (Manenschijn et al., 2011a) and test-retest reliability (Stalder et al., 2012) of hair cortisol concentration as a marker of chronic cortisol exposure.

Information on age, sex, ethnicity, household non-pension wealth (a sensitive indicator of socio-economic status (SES) in this age group (Demakakos et al., 2015)), smoking status (current smoker vs. former/nonsmoker) and hair treatment (dyeing or chemical treatment, such as perming or chemical straightening) was self-reported by participants. Depressive symptoms were assessed using an 8-item version of the Center for Epidemiologic Studies Depression scale (Radloff, 1977; Turvey et al., 1999), which is scored from 0 (no depressive symptoms) to 8 (highest number of depressive symptoms).

\section{Statistical analysis}

Analyses were performed using STATA version 13.1 (STATA Corporation, College Station, TX, USA). Hair cortisol data were log transformed to correct skewness. All analyses adjusted for confounding by age, sex, ethnicity, SES, smoking status, hair treatment and depressive symptoms as these factors have been identified in the literature as covariates for hair cortisol (Stalder et al., 2017). Logistic regression was used to test the association between obesity and perceived weight discrimination, and analysis of covariance (ANCOVA) to test for differences in mean hair cortisol concentration by obesity and perceived weight discrimination. Mediation analyses were used to test the hypothesis that perceived weight discrimination mediated the relationship between obesity and hair cortisol concentration (Figure 1). The mediation model was also run using a continuous measure of BMI to compare results. The sgmediation command in STATA was used, which calculates total, direct, and indirect effects, and tests the significance of the indirect effect 
using the Sobel test (Baron and Kenny, 1986; Sobel, 1982). The total effect (path c) of an independent variable (IV) on a dependent variable (DV) consists of a direct effect (path $c^{\prime}$ ) of the IV on the DV and an indirect effect (path $a \times b$ ) of the IV on the DV via a proposed mediator. Path $a$ represents the effect of the IV on the mediator, and path $b$ is the effect of the mediator on the DV. In the present analyses, obesity was the IV, hair cortisol concentration was the DV and perceived weight discrimination was the mediator. The 95\% confidence interval $[\mathrm{Cl}]$ was estimated using bootstrapping with 5000 sampling replications (DeRosia, n.d.; Preacher and Hayes, 2004); a method considered preferable to the Sobel tests for testing the significance of indirect effects because it does not assume a normal distribution and therefore reduces the likelihood of type 2 error (Preacher and Hayes, 2004; Shrout and Bolger, 2002). A 95\% Cl that does not include 0 indicates a significant indirect effect at $p<.05$ (Preacher and Hayes, 2004). The proportion of the total effect of obesity on hair cortisol concentration explained by perceived weight discrimination was indicated by the effect ratio produced by the sgmediation command; effect ratios of $0.25,0.5$ and 0.75 indicate that a quarter, half, and three-quarters of the total effect is explained by the mediator, respectively (Shrout and Bolger, 2002).

\section{[Figure 1 about here]}

Given that BMI was measured four years prior to the hair cortisol measurement and two year prior to the discrimination measurement, sensitivity analyses were conducted to examine the impact of any change in weight over the study period. Change in BMI between Wave 4 (the time at which the BMI data of interest in the present study were collected) and Wave 6 (the time of the hair cortisol measurements) was examined using a paired $t$-test and the mediation models were repeated adjusting for Wave 6 BMI.

Further analyses were conducted in order to explore whether similar effects were found for other forms of discrimination or were unique to weight discrimination. Models were run testing for mediation of associations between obesity/BMI and hair cortisol by two other types of perceived discrimination; ageism 
and sexism (with variables created following the same method as the weight discrimination measure). These were selected because they were the most prevalent forms of perceived discrimination reported by the sample, at $27.3 \%$ and $7.7 \%$ respectively.

Models were also run testing for mediation in a different direction (with obesity as the IV, perceived weight discrimination as the DV and hair cortisol concentration as the mediator) in order to explore whether greater stress exposure leads to heightened vigilance for discrimination.

\section{Results}

Table 1 presents data on sample characteristics. The mean age of participants was 68.4 years, $60.4 \%$ were female, $98.8 \%$ identified as white, and $9.8 \%$ were smokers. The mean BMI was $28.2 \mathrm{~kg} / \mathrm{m}^{2}$, and $30.8 \%$ of participants were living with obesity. Individuals with obesity were on average slightly less wealthy $(p<$ $.001)$, less likely to smoke $(p=.049)$ and reported a greater number of depressive symptoms $(p<.001)$ than the non-obese group, but the groups did not differ significantly by age, sex or ethnicity. Weight discrimination was reported by $3.9 \%$ of participants, but was strongly related to weight status with $10.9 \%$ of individuals with obesity reporting weight discrimination compared with just $0.7 \%$ of those with a non-obese BMI (adjusted OR = 15.66, 95\% Cl 7.58-32.36, $p<.001$ ).

[Table 1 about here]

Obesity and perceived weight discrimination were significantly associated with hair cortisol. There was a significant positive correlation between $\mathrm{BMI}$ and hair cortisol $(r=0.076, p=.001)$, and individuals with obesity had a higher mean [SE] hair cortisol concentration than those who were not obese $(0.98$ [0.03] vs. $0.87[0.02] \log \mathrm{pg} / \mathrm{mg} ; F=11.60, p<.001)$. Likewise, people who reported experiences of weight 
discrimination also had a significantly higher mean [SE] hair cortisol concentration than those who did not report weight discrimination (1.15 [0.07] vs. $0.90[0.01] \log \mathrm{pg} / \mathrm{mg} ; F=4.18, p=.001)$.

Table 2 summarizes the results of the mediation analyses (path c, path $c^{\prime}$, and indirect effects in Figure 1). There was a significant indirect effect of obesity via weight discrimination on hair cortisol concentration $(\beta=$ $0.021, \mathrm{SE}=0.007,95 \% \mathrm{Cl} 0.007-0.036)$. The effect ratio indicated that perceived weight discrimination explained just under $20 \%$ of the total effect of obesity on hair cortisol. There was also a direct effect of obesity on hair cortisol concentration $(\beta=0.089, \mathrm{SE}=0.031$ ). Similar findings were observed when $\mathrm{BMI}$ was entered into the model in place of obesity, with results showing a significant indirect effect via weight discrimination $(\beta=0.001, \mathrm{SE}=0.0004,95 \% \mathrm{Cl} 0.0004-0.002)$ that explained $23 \%$ of the total effect of $\mathrm{BMI}$ on hair cortisol, and a direct effect of $\mathrm{BMI}$ on hair cortisol $(\beta=0.004, \mathrm{SE}=0.002)$.

[Table 2 about here]

Comparison of BMI measurements at Wave 4 (the BMI data used for the primary analyses in this study) and Wave 6 (the wave in which hair cortisol concentrations were measured) showed a small but significant mean reduction in BMI over time, from 28.15 (SD 5.13) to 27.40 (SD 6.70; $p<.001$ ). Sensitivity analyses indicated that adjusting for BMI at the latter time point had a negligible impact on the mediation results (Supplemental Table 1).

Analyses testing for mediation by perceived age discrimination and perceived sex discrimination indicated that while these forms of discrimination were both significantly associated with higher hair cortisol concentrations, there was no evidence that they mediated the effect of obesity on hair cortisol (Table 3).

[Table 3 about here] 
Reverse mediation models were also tested in order to examine whether reports of weight discrimination by individuals with obesity/high BMI could be explained by their higher stress levels [Table 4]. These revealed direct effects of obesity and BMI on perceived weight discrimination and very small indirect effects of hair cortisol (obesity: $\beta=0.002, \mathrm{SE}=0.0009,95 \% \mathrm{Cl}=0.0002$ to $0.004 ; \mathrm{BMI}: \beta=0.0001, \mathrm{SE}=0.00006,95 \%$ $\mathrm{Cl}=0.00002$ to 0.0003 ) that explained $2.7-2.8 \%$ of the association between obesity/BMI and perceived weight discrimination.

[Table 4 about here]

\section{Discussion}

Obesity and perceived weight discrimination were independently associated with elevated hair cortisol concentrations in this population-based sample of English middle-aged and older adults. These associations have previously been described (Jackson et al., 2017, 2016). Importantly, the association between obesity and hair cortisol was mediated by perceptions of weight discrimination, with results indicating that weightrelated discrimination explains just under a fifth of the total effect of obesity (BMI $\geq 30$ ), and almost a quarter of the effect of BMI (as a continuous variable), on chronic stress. Effects appeared to be unique to weight-related discrimination, with sensitivity analyses showing no evidence of mediation by other types of discrimination despite similar adverse effects on stress levels. These findings provide support for theories implicating weight stigma in the relationship between obesity and stress (Tomiyama, 2014), and add to the growing body of literature illustrating the significant impact of weight stigma on health and wellbeing (Puhl and Suh, 2015).

This study had a number of limitations. First, the perception of weight discrimination is dependent on the interpretation of the intentions of others. As such, it is possible that some individuals perceive that they 
have been discriminated against as a result of their weight when this is not the case, while others fail to perceive discrimination that occurs or to attribute experiences of discrimination to their weight when this was the underlying reason. Previous research has suggested that whether or not a person perceives discrimination may be influenced by their mental state (Phinney et al., 1998), so further mediation models were performed in the present sample to explore whether greater stress leads to higher vigilance for discrimination. While hair cortisol concentrations were found to significantly mediate relationships between obesity, BMI and perceived weight discrimination, effects were small and explained less than $3 \%$ of these associations, suggesting there are other important factors (e.g. self-perception of overweight) that explain the higher prevalence of perceived weight discrimination among heavier individuals. Second, the mediator (discrimination) was measured two years after BMI, and the outcome (cortisol) was assessed two years after that. While this provides a temporal sequence suited to testing a causal model, the spacing of several years between measurements is not optimal given that the measure of cortisol only reflected stress levels over the last two months. On average, participants' BMI decreased slightly over the study period (as would be expected in an older sample (Williamson, 1993)), although sensitivity analyses adjusting for BMI at the latter time point indicated that this weight change had little impact on the results. Replication of the present findings over a shorter time frame is required to confirm the conclusions drawn. It should also be noted that statistical mediation does not imply causality. Third, results may not generalize to other populations. Participants were from an older sample, in which levels of cortisol, cortisol-associated health conditions, experiences of weight discrimination and societal attitudes towards overweight and obesity may differ relative to younger age groups (Andreyeva et al., 2008; Feller et al., 2014). In addition, the sample was almost exclusively of white ethnic origin, so findings may not extend to other ethnic groups. Weight data were not available for the whole ELSA sample and it is possible that refusal to be weighed was more likely among those most troubled by their weight. Fourth, we did not exclude participants using corticosteroids, which are known to slightly decrease cortisol concentrations (Dahl, 2006), which may mean 
findings were underestimated. Finally, as a measure of body composition BMI has flaws (Burkhauser and Cawley, 2008) and other measures of adiposity such as waist circumference or waist-to-hip ratio may be relevant, particularly as abdominal obesity appears to be more consistently related to indices of cortisol (Incollingo Rodriguez et al., 2015). More accurate measures such as dual-energy X-ray absorptiometry are not collected in the ELSA sample.

This study also had several strengths. Data were drawn from a large, nationally-representative cohort, in which rates of weight discrimination were comparable to the equivalent age group in other samples (Puhl et al., 2008). While many large longitudinal studies rely on self-reported data, height and weight are objectively measured in ELSA. The collection of hair samples provided insight into chronic exposure to cortisol; this is not captured by traditional assays in saliva, urine or serum which are vulnerable to fluctuations due to the circadian rhythm, pulsatile secretion and daily variation arising from situational factors (e.g. diet, environmental stressors or infection). The use of LC/MS (a very sensitive detection technique) to detect hair cortisol concentrations was also a strength. The items used to assess discrimination limited reporting bias among respondents with obesity by asking generally about experiences of discrimination at first and then including weight among a list of other possible attributions for discrimination.

The present results indicate that weight discrimination is an important mediator of the association between obesity and physiological stress. On this basis, it may be possible to somewhat reduce the psychological and physiological burden of obesity by targeting the stigmatization of, and discrimination against, individuals living with obesity or by developing interventions that promote adaptive coping responses to reduce stress. Although obesity has many physiological health comorbidities independent of stigma, chronic psychological stress is a risk factor for a number of diseases that commonly accompany obesity, including cardiovascular disease and depression (Cohen S et al., 2007). Moreover, a recent study indicated that people with obesity 
who internalize weight bias (i.e. self-stigmatize) may have greater cardiometabolic risk (Pearl et al., 2017). In addition, the stress response to weight stigma may promote weight gain through influences on behavior and internal regulatory processes, thus perpetuating a cycle of stigma and obesity and increasing the risk of morbidity and mortality. In 2014, Tomiyama proposed a Cyclic Obesity/Weight-Based Stigma (COBWEBS) model which describes a "vicious cycle" of obesity, weight stigma and stress (Tomiyama, 2014). The COBWEBS model posits that obesity exposes individuals to weight stigma and discrimination, which acts as a stressor, activating the hypothalamic-pituitary-adrenal (HPA) axis and triggering predictable biochemical, physiological, cognitive and behavioral changes, including release of cortisol, accumulation and retention of abdominal fat (Peckett et al., 2011), and upregulation of appetite and drive to consume energy-dense "comfort" foods (Born et al., 2010; Groesz et al., 2012; Kandiah et al., 2006). These changes promote weight gain and inhibit weight loss, contributing to obesity, and thus the cycle continues. There is currently limited evidence on effective strategies for reducing weight bias (Daníelsdóttir et al., 2010; Lee et al., 2014), although a recent study indicates that interventions that evoke empathy and encourage perspective-taking may have the potential to alter affective reactions toward people with obesity (Gloor and Puhl, 2016).

In summary, the findings of this study suggest that addressing weight bias could have significant implications for the health and wellbeing of individuals with obesity, and add support to calls for further research dedicated to designing and testing stigma-reduction interventions. 


\section{Acknowledgments}

This work was supported by a grant from Cancer Research UK (C1418/A14133). 


\section{References}

Anagnostis, P., Athyros, V.G., Tziomalos, K., Karagiannis, A., Mikhailidis, D.P., 2009. The Pathogenetic Role of Cortisol in the Metabolic Syndrome: A Hypothesis. J. Clin. Endocrinol. Metab. 94, 2692-2701. https://doi.org/10.1210/jc.2009-0370

Andreyeva, T., Puhl, R.M., Brownell, K.D., 2008. Changes in Perceived Weight Discrimination Among Americans, 1995-1996 Through 2004-2006. Obesity 16, 1129-1134. https://doi.org/10.1038/oby.2008.35

Baron, R.M., Kenny, D.A., 1986. The moderator-mediator variable distinction in social psychological research: Conceptual, strategic, and statistical considerations. J. Pers. Soc. Psychol. 51, 1173.

Björntorp, P., 2001. Do stress reactions cause abdominal obesity and comorbidities? Obes. Rev. 2, 73-86. https://doi.org/10.1046/j.1467-789x.2001.00027.x

Born, J.M., Lemmens, S.G.T., Rutters, F., Nieuwenhuizen, A.G., Formisano, E., Goebel, R., WesterterpPlantenga, M.S., 2010. Acute stress and food-related reward activation in the brain during food choice during eating in the absence of hunger. Int. J. Obes. 34, 172-181. https://doi.org/10.1038/ijo.2009.221

Burkhauser, R.V., Cawley, J., 2008. Beyond BMI: The value of more accurate measures of fatness and obesity in social science research. J. Health Econ. 27, 519-529. https://doi.org/10.1016/j.jhealeco.2007.05.005

Cohen S, Janicki-Deverts D, Miller GE, 2007. Psychological stress and disease. JAMA 298, 1685-1687. https://doi.org/10.1001/jama.298.14.1685

Dahl, R., 2006. Systemic side effects of inhaled corticosteroids in patients with asthma. Respir. Med. 100, 1307-1317. https://doi.org/10.1016/j.rmed.2005.11.020

Dallman, M.F., Pecoraro, N., Akana, S.F., Fleur, S.E. la, Gomez, F., Houshyar, H., Bell, M.E., Bhatnagar, S., Laugero, K.D., Manalo, S., 2003. Chronic stress and obesity: A new view of "comfort food." Proc. Natl. Acad. Sci. 100, 11696-11701. https://doi.org/10.1073/pnas.1934666100

Daníelsdóttir, S., O’Brien, K.S., Ciao, A., 2010. Anti-fat prejudice reduction: a review of published studies. Obes. Facts 3, 47-58. https://doi.org/10.1159/000277067

Demakakos, P., Biddulph, J.P., Bobak, M., Marmot, M.G., 2015. Wealth and mortality at older ages: a prospective cohort study. J. Epidemiol. Community Health jech-2015-206173. https://doi.org/10.1136/jech-2015-206173

DeRosia, E.D., n.d. Stata code for performing the Preacher and Hayes bootstrapped test of mediation |.

Feller, S., Vigl, M., Bergmann, M.M., Boeing, H., Kirschbaum, C., Stalder, T., 2014. Predictors of hair cortisol concentrations in older adults. Psychoneuroendocrinology 39, 132-140. https://doi.org/10.1016/j.psyneuen.2013.10.007

Gao, W., Stalder, T., Foley, P., Rauh, M., Deng, H., Kirschbaum, C., 2013. Quantitative analysis of steroid hormones in human hair using a column-switching LC-APCI-MS/MS assay. J. Chromatogr. B Analyt. Technol. Biomed. Life. Sci. 928, 1-8. https://doi.org/10.1016/j.jchromb.2013.03.008

Gloor, J.L., Puhl, R.M., 2016. Empathy and Perspective-Taking: Examination and Comparison of Strategies to Reduce Weight Stigma. Stigma Health. https://doi.org/10.1037/sah0000030

Groesz, L.M., McCoy, S., Carl, J., Saslow, L., Stewart, J., Adler, N., Laraia, B., Epel, E., 2012. What is eating you? Stress and the drive to eat. Appetite 58, 717-721. https://doi.org/10.1016/j.appet.2011.11.028

Hatzenbuehler, M.L., Keyes, K.M., Hasin, D.S., 2009. Associations between perceived weight discrimination and the prevalence of psychiatric disorders in the general population. Obes. Silver Spring Md 17, 2033-2039. https://doi.org/10.1038/oby.2009.131 
Himmelstein, M.S., Incollingo Belsky, A.C., Tomiyama, A.J., 2015. The weight of stigma: cortisol reactivity to manipulated weight stigma. Obes. Silver Spring Md 23, 368-374.

https://doi.org/10.1002/oby.20959

Incollingo Rodriguez, A.C., Epel, E.S., White, M.L., Standen, E.C., Seckl, J.R., Tomiyama, A.J., 2015. Hypothalamic-pituitary-adrenal axis dysregulation and cortisol activity in obesity: A systematic review. Psychoneuroendocrinology 62, 301-318. https://doi.org/10.1016/j.psyneuen.2015.08.014

Jackson, S.E., Beeken, R.J., Wardle, J., 2015a. Obesity, perceived weight discrimination, and psychological well-being in older adults in England. Obesity 23, 1105-1111. https://doi.org/10.1002/oby.21052

Jackson, S.E., Beeken, R.J., Wardle, J., 2014. Perceived weight discrimination and changes in weight, waist circumference, and weight status. Obesity 22, 2485-2488. https://doi.org/10.1002/oby.20891

Jackson, S.E., Kirschbaum, C., Steptoe, A., 2017. Hair cortisol and adiposity in a population-based sample of 2,527 men and women aged 54 to 87 years. Obesity $25,539-544$. https://doi.org/10.1002/oby.21733

Jackson, S.E., Kirschbaum, C., Steptoe, A., 2016. Perceived weight discrimination and chronic biochemical stress: A population-based study using cortisol in scalp hair. Obes. Silver Spring Md 24, 2515-2521. https://doi.org/10.1002/oby.21657

Jackson, S.E., Steptoe, A., Beeken, R.J., Croker, H., Wardle, J., 2015b. Perceived weight discrimination in England: a population-based study of adults aged $\geqslant 50$ years. Int. J. Obes. $39,858-864$. https://doi.org/10.1038/ijo.2014.186

Kandiah, J., Yake, M., Jones, J., Meyer, M., 2006. Stress influences appetite and comfort food preferences in college women. Nutr. Res. 26, 118-123. https://doi.org/10.1016/j.nutres.2005.11.010

Kintz, P., Villain, M., Cirimele, V., 2006. Hair Analysis for Drug Detection: Ther. Drug Monit. 28, 442-446. https://doi.org/10.1097/01.ftd.0000211811.27558.b5

Lee, M., Ata, R.N., Brannick, M.T., 2014. Malleability of weight-biased attitudes and beliefs: A meta-analysis of weight bias reduction interventions. Body Image 11, 251-259.

https://doi.org/10.1016/j.bodyim.2014.03.003

Manenschijn, L., Koper, J.W., Lamberts, S.W.J., van Rossum, E.F.C., 2011a. Evaluation of a method to measure long term cortisol levels. Steroids 76, 1032-1036. https://doi.org/10.1016/j.steroids.2011.04.005

Manenschijn, L., van Kruysbergen, R.G.P.M., de Jong, F.H., Koper, J.W., van Rossum, E.F.C., 2011b. Shift Work at Young Age Is Associated with Elevated Long-Term Cortisol Levels and Body Mass Index. J. Clin. Endocrinol. Metab. 96, E1862-E1865. https://doi.org/10.1210/jc.2011-1551

Ng, M., Fleming, T., Robinson, M., Thomson, B., Graetz, N., Margono, C., Mullany, E.C., Biryukov, S., Abbafati, C., Abera, S.F., Abraham, J.P., Abu-Rmeileh, N.M.E., Achoki, T., AlBuhairan, F.S., Alemu, Z.A., Alfonso, R., Ali, M.K., Ali, R., Guzman, N.A., Ammar, W., Anwari, P., Banerjee, A., Barquera, S., Basu, S., Bennett, D.A., Bhutta, Z., Blore, J., Cabral, N., Nonato, I.C., Chang, J.-C., Chowdhury, R., Courville, K.J., Criqui, M.H., Cundiff, D.K., Dabhadkar, K.C., Dandona, L., Davis, A., Dayama, A., Dharmaratne, S.D., Ding, E.L., Durrani, A.M., Esteghamati, A., Farzadfar, F., Fay, D.F.J., Feigin, V.L., Flaxman, A., Forouzanfar, M.H., Goto, A., Green, M.A., Gupta, R., Hafezi-Nejad, N., Hankey, G.J., Harewood, H.C., Havmoeller, R., Hay, S., Hernandez, L., Husseini, A., Idrisov, B.T., Ikeda, N., Islami, F., Jahangir, E., Jassal, S.K., Jee, S.H., Jeffreys, M., Jonas, J.B., Kabagambe, E.K., Khalifa, S.E.A.H., Kengne, A.P., Khader, Y.S., Khang, Y.-H., Kim, D., Kimokoti, R.W., Kinge, J.M., Kokubo, Y., Kosen, S., Kwan, G., Lai, T., Leinsalu, M., Li, Y., Liang, X., Liu, S., Logroscino, G., Lotufo, P.A., Lu, Y., Ma, J., Mainoo, N.K., Mensah, G.A., Merriman, T.R., Mokdad, A.H., Moschandreas, J., Naghavi, M., Naheed, A., Nand, D., Narayan, K.M.V., Nelson, E.L., Neuhouser, M.L., Nisar, M.I., Ohkubo, T., Oti, S.O., Pedroza, A., Prabhakaran, D., Roy, N., Sampson, U., Seo, H., Sepanlou, S.G., Shibuya, K., Shiri, R., Shiue, I., Singh, G.M., Singh, J.A., Skirbekk, V., Stapelberg, N.J.C., Sturua, L., Sykes, B.L., Tobias, M., Tran, B.X., Trasande, L., Toyoshima, H., van de Vijver, S., Vasankari, T.J., Veerman, J.L., Velasquez- 
Melendez, G., Vlassov, V.V., Vollset, S.E., Vos, T., Wang, C., Wang, X., Weiderpass, E., Werdecker, A., Wright, J.L., Yang, Y.C., Yatsuya, H., Yoon, J., Yoon, S.-J., Zhao, Y., Zhou, M., Zhu, S., Lopez, A.D., Murray, C.J.L., Gakidou, E., 2014. Global, regional, and national prevalence of overweight and obesity in children and adults during 1980-2013: a systematic analysis for the Global Burden of Disease Study 2013. The Lancet 384, 766-781. https://doi.org/10.1016/S0140-6736(14)60460-8

Noppe, G., van den Akker, E.L.T., de Rijke, Y.B., Koper, J.W., Jaddoe, V.W., van Rossum, E.F.C., 2016. Longterm glucocorticoid concentrations as a risk factor for childhood obesity and adverse body-fat distribution. Int. J. Obes. https://doi.org/10.1038/ijo.2016.113

Pearl, R.L., Wadden, T.A., Hopkins, C.M., Shaw, J.A., Hayes, M.R., Bakizada, Z.M., Alfaris, N., Chao, A.M., Pinkasavage, E., Berkowitz, R.I., Alamuddin, N., 2017. Association between weight bias internalization and metabolic syndrome among treatment-seeking individuals with obesity. Obesity 25, 317-322. https://doi.org/10.1002/oby.21716

Peckett, A.J., Wright, D.C., Riddell, M.C., 2011. The effects of glucocorticoids on adipose tissue lipid metabolism. Metabolism 60, 1500-1510. https://doi.org/10.1016/j.metabol.2011.06.012

Pervanidou, P., Chrousos, G.P., 2011. Stress and obesity/metabolic syndrome in childhood and adolescence. Int. J. Pediatr. Obes. 6, 21-28.

Phinney, J.S., Madden, T., Santos, L.J., 1998. Psychological Variables as Predictors of Perceived Ethnic Discrimination Among Minority and Immigrant Adolescents1. J. Appl. Soc. Psychol. 28, 937-953. https://doi.org/10.1111/j.1559-1816.1998.tb01661.x

Preacher, K.J., Hayes, A.F., 2004. SPSS and SAS procedures for estimating indirect effects in simple mediation models. Behav. Res. Methods Instrum. Comput. 36, 717-731.

Puhl, R., Suh, Y., 2015. Health Consequences of Weight Stigma: Implications for Obesity Prevention and Treatment. Curr. Obes. Rep. 4, 182-190. https://doi.org/10.1007/s13679-015-0153-z

Puhl, R.M., Andreyeva, T., Brownell, K.D., 2008. Perceptions of weight discrimination: prevalence and comparison to race and gender discrimination in America. Int. J. Obes. 32, 992-1000. https://doi.org/10.1038/ijo.2008.22

Puhl, R.M., Brownell, K.D., 2006. Confronting and coping with weight stigma: an investigation of overweight and obese adults. Obes. Silver Spring Md 14, 1802-1815. https://doi.org/10.1038/oby.2006.208

Puhl, R.M., Brownell, K.D., 2001. Bias, Discrimination, and Obesity. Obesity 9, 788-805.

Puhl, R.M., Heuer, C.A., 2009. The stigma of obesity: a review and update. Obesity 17, 941-964.

Radloff, L.S., 1977. The CES-D scale. Appl Psychol Meas 1, 385-401.

Schvey, N.A., Puhl, R.M., Brownell, K.D., 2014. The stress of stigma: exploring the effect of weight stigma on cortisol reactivity. Psychosom. Med. 76, 156-162. https://doi.org/10.1097/PSY.0000000000000031

Seacat, J.D., Dougal, S.C., Roy, D., 2014. A daily diary assessment of female weight stigmatization. J. Health Psychol. 21, 228-240. https://doi.org/10.1177/1359105314525067

Shrout, P.E., Bolger, N., 2002. Mediation in experimental and nonexperimental studies: new procedures and recommendations. Psychol. Methods 7, 422-445.

Sobel, M.E., 1982. Asymptotic confidence intervals for indirect effects in structural equation models. Sociol. Methodol. 13, 290-312.

Stalder, T., Kirschbaum, C., 2012. Analysis of cortisol in hair--state of the art and future directions. Brain. Behav. Immun. 26, 1019-1029. https://doi.org/10.1016/j.bbi.2012.02.002

Stalder, T., Steudte, S., Miller, R., Skoluda, N., Dettenborn, L., Kirschbaum, C., 2012. Intraindividual stability of hair cortisol concentrations. Psychoneuroendocrinology 37, 602-610. https://doi.org/10.1016/j.psyneuen.2011.08.007

Stalder, T., Steudte-Schmiedgen, S., Alexander, N., Klucken, T., Vater, A., Wichmann, S., Kirschbaum, C., Miller, R., 2017. Stress-related and basic determinants of hair cortisol in humans: A meta-analysis. Psychoneuroendocrinology 77, 261-274. https://doi.org/10.1016/j.psyneuen.2016.12.017 
Steptoe, A., Breeze, E., Banks, J., Nazroo, J., 2013. Cohort profile: the English Longitudinal Study of Ageing. Int. J. Epidemiol. 42, 1640-1648. https://doi.org/10.1093/ije/dys168

Tomiyama, A.J., 2014. Weight stigma is stressful. A review of evidence for the Cyclic Obesity/Weight-Based Stigma model. Appetite 82, 8-15. https://doi.org/10.1016/j.appet.2014.06.108

Tomiyama, A.J., Epel, E.S., McClatchey, T.M., Poelke, G., Kemeny, M.E., McCoy, S.K., Daubenmier, J., 2014. Associations of weight stigma with cortisol and oxidative stress independent of adiposity. Health Psychol. Off. J. Div. Health Psychol. Am. Psychol. Assoc. 33, 862-867. https://doi.org/10.1037/hea0000107

Torres, S.J., Nowson, C.A., 2007. Relationship between stress, eating behavior, and obesity. Nutrition 23, 887-894. https://doi.org/10.1016/j.nut.2007.08.008

Turvey, C.L., Wallace, R.B., Herzog, R., 1999. A revised CES-D measure of depressive symptoms and a DSMbased measure of major depressive episodes in the elderly. Int. Psychogeriatr. IPA 11, 139-148.

Vartanian, L.R., Pinkus, R.T., Smyth, J.M., 2014. The phenomenology of weight stigma in everyday life. J. Context. Behav. Sci. 3, 196-202. https://doi.org/10.1016/j.jcbs.2014.01.003

Veldhorst, M.A.B., Noppe, G., Jongejan, M.H.T.M., Kok, C.B.M., Mekic, S., Koper, J.W., van Rossum, E.F.C., van den Akker, E.L.T., 2013. Increased Scalp Hair Cortisol Concentrations in Obese Children. J. Clin. Endocrinol. Metab. 99, 285-290. https://doi.org/10.1210/jc.2013-2924

Wester, V.L., Staufenbiel, S.M., Veldhorst, M.A.B., Visser, J.A., Manenschijn, L., Koper, J.W., KlessensGodfroy, F.J.M., van den Akker, E.L.T., van Rossum, E.F.C., 2014. Long-term cortisol levels measured in scalp hair of obese patients. Obesity 22, 1956-1958. https://doi.org/10.1002/oby.20795

Williamson, D.F., 1993. Descriptive Epidemiology of Body Weight and Weight Change in U.S. Adults. Ann. Intern. Med. 119, 646-649. https://doi.org/10.1059/0003-4819-119-7_Part_2-199310011-00004 


\section{Tables}

\begin{tabular}{|c|c|c|c|c|}
\hline & $\begin{array}{l}\text { Whole sample } \\
(n=1872)\end{array}$ & $\begin{array}{c}\text { Non-obese } \\
(n=1295)\end{array}$ & $\begin{array}{l}\text { Obese } \\
(n=577)\end{array}$ & $p$ \\
\hline Age (years) & $68.37 \pm 7.37$ & $68.49 \pm 7.35$ & $68.09 \pm 7.42$ & 271 \\
\hline \multicolumn{5}{|l|}{ Sex } \\
\hline Men & $39.6(742)$ & $40.4(523)$ & 38.0 (219) & .321 \\
\hline Women & $60.4(1130)$ & $59.6(772)$ & $62.0(358)$ & - \\
\hline \multicolumn{5}{|l|}{ Ethnicity } \\
\hline White & $98.8(1849)$ & $98.6(1277)$ & $98.5(572)$ & .342 \\
\hline Non-white & $1.2(23)$ & $1.4(18)$ & $1.5(5)$ & - \\
\hline \multicolumn{5}{|l|}{ Wealth quintile } \\
\hline 1 (poorest) & $12.1(223)$ & $10.3(131)$ & $16.1(92)$ & $<.001$ \\
\hline 2 & $16.9(312)$ & $15.0(191)$ & $21.2(121)$ & - \\
\hline 3 & $21.7(400)$ & $20.4(260)$ & $24.5(140)$ & - \\
\hline 4 & $23.5(433)$ & $24.9(317)$ & $20.3(116)$ & - \\
\hline 5 (richest) & $25.9(477)$ & $29.4(374)$ & $18.0(103)$ & - \\
\hline BMI $\left(\mathrm{kg} / \mathrm{m}^{2}\right)$ & $28.15 \pm 5.13$ & $25.46 \pm 2.66$ & $34.19 \pm 4.09$ & $<.001$ \\
\hline \multicolumn{5}{|l|}{ Weight status } \\
\hline Underweight & $0.7(13)$ & $1.0(13)$ & - & $<.001$ \\
\hline Normal-weight & $27.3(511)$ & $39.5(511)$ & - & - \\
\hline Overweight & $41.2(771)$ & $59.5(771)$ & - & - \\
\hline Obese & $30.8(577)$ & - & $100.0(577)$ & - \\
\hline \multicolumn{5}{|l|}{ Perceived weight discrimination } \\
\hline Yes & $3.9(72)$ & $0.7(9)$ & $10.9(63)$ & $<.001$ \\
\hline No & $95.4(1785)$ & $99.3(1293)$ & $89.1(514)$ & - \\
\hline \multicolumn{5}{|l|}{ Smoking status } \\
\hline Current smoker & $9.8(184)$ & 10.7 (139) & $7.8(45)$ & .049 \\
\hline Former/non-smoker & $90.2(1688)$ & $89.3(1156)$ & $92.2(532)$ & - \\
\hline Depressive symptoms & $1.16(1.73)$ & $1.36(0.08)$ & $1.06(0.05)$ & $<.001$ \\
\hline \multicolumn{5}{|l|}{ Hair treatment } \\
\hline Yes & $35.0(654)$ & $35.2(455)$ & 34.5 (199) & .771 \\
\hline No & $65.0(1213)$ & $64.8(836)$ & $65.5(377)$ & - \\
\hline Hair cortisol concentration (log $\mathrm{pg} / \mathrm{mg}$ ) & $0.91 \pm 0.63$ & $0.88 \pm 0.62$ & $0.99 \pm 0.63$ & $<.001$ \\
\hline
\end{tabular}

Note: numbers may not sum to total sample number due to missing data. Valid percentages are shown for ease of interpretation. Underweight, $\mathrm{BMI}<18.5 \mathrm{~kg} / \mathrm{m}^{2}$; normal-weight, $\mathrm{BMI} 18.5-24.9 \mathrm{~kg} / \mathrm{m}^{2}$; overweight, $\mathrm{BMI} 25-29.9 \mathrm{~kg} / \mathrm{m}^{2} ;$ obese, $\mathrm{BMI} \geq 30 \mathrm{~kg} / \mathrm{m}^{2}$. 
Table 2 Models testing mediation of the associations between obesity/body mass index and hair cortisol concentration by perceived weight discrimination (see Figure 1 )

\begin{tabular}{|c|c|c|c|c|c|}
\hline & Coeff. & SE & $p^{*}$ & Bootstrap 95\% Cl & Effect ratio \\
\hline \multicolumn{6}{|l|}{ Obesity } \\
\hline Total effect (path $c$ ) & 0.111 & 0.031 & $<.001$ & - & - \\
\hline Direct effect (path $c^{\prime}$ ) & 0.089 & 0.031 & .004 & - & - \\
\hline Indirect effect (via mediator) & 0.021 & 0.007 & .001 & {$[0.007 ; 0.036]$} & 0.194 \\
\hline \multicolumn{6}{|l|}{ BMI } \\
\hline Total effect (path $c$ ) & 0.006 & 0.002 & .005 & - & - \\
\hline Direct effect (path $c^{\prime}$ ) & 0.004 & 0.002 & .034 & - & - \\
\hline Indirect effect (via mediator) & 0.001 & 0.0004 & $<.001$ & {$[0.0004 ; 0.002]$} & 0.230 \\
\hline \multicolumn{6}{|c|}{$\begin{array}{l}\text { * } p \text { values shown for indirect effects are derived from the Sobel test for consistency with total and direct } \\
\text { effects, however bootstrap } 95 \% \text { confidence intervals provide a more robust indication of significant mediation } \\
\text { (see Method for more details). }\end{array}$} \\
\hline
\end{tabular}


Table 3 Models testing mediation of the associations between obesity/body mass index and hair cortisol concentration by perceived age and sex discrimination

\begin{tabular}{|c|c|c|c|c|c|}
\hline & Coeff. & SE & $p^{*}$ & Bootstrap 95\% Cl & Effect ratio \\
\hline \multicolumn{6}{|l|}{ Age discrimination } \\
\hline \multicolumn{6}{|l|}{ Obesity } \\
\hline Total effect (path $c$ ) & 0.111 & 0.031 & $<.001$ & - & - \\
\hline Direct effect (path $c^{\prime}$ ) & 0.110 & 0.031 & $<.001$ & - & - \\
\hline Indirect effect (via mediator) & 0.001 & 0.001 & .433 & {$[-0.002 ; 0.005]$} & 0.010 \\
\hline \multicolumn{6}{|l|}{ BMI } \\
\hline Total effect (path $c$ ) & 0.005 & 0.002 & .005 & - & - \\
\hline Direct effect (path $c^{\prime}$ ) & 0.006 & 0.002 & .006 & - & - \\
\hline Indirect effect (via mediator) & 0.00006 & 0.00007 & .450 & {$[-0.00008 ; 0.0003]$} & 0.010 \\
\hline \multicolumn{6}{|l|}{ Sex discrimination } \\
\hline \multicolumn{6}{|l|}{ Obesity } \\
\hline Total effect (path $c$ ) & 0.111 & 0.031 & $<.001$ & - & - \\
\hline Direct effect (path $c^{\prime}$ ) & 0.110 & 0.031 & $<.001$ & - & - \\
\hline Indirect effect (via mediator) & 0.0005 & 0.0008 & .539 & {$[-0.001 ; 0.003]$} & 0.005 \\
\hline \multicolumn{6}{|l|}{ BMI } \\
\hline Total effect (path $c$ ) & 0.006 & 0.002 & .005 & - & - \\
\hline Direct effect (path $c^{\prime}$ ) & 0.006 & 0.002 & .006 & - & - \\
\hline Indirect effect (via mediator) & 0.00003 & 0.00005 & .558 & {$[-0.00008 ; 0.0002]$} & 0.005 \\
\hline \multicolumn{6}{|c|}{ Analyses are adjusted for age, sex, ethnicity, wealth, smoking status, hair treatment and depressive symptoms. } \\
\hline \multicolumn{6}{|c|}{$\begin{array}{l}* p \text { values shown for indirect effects are derived from the Sobel test for consistency with total and direct effects, } \\
\text { however bootstrap } 95 \% \text { confidence intervals provide a more robust indication of significant mediation (see }\end{array}$} \\
\hline
\end{tabular}


Table 4 Models testing mediation of the associations between obesity/body mass index and perceived weight discrimination by hair cortisol concentration

\begin{tabular}{|c|c|c|c|c|c|}
\hline & Coeff. & SE & $p^{*}$ & Bootstrap 95\% Cl & Effect ratio \\
\hline \multicolumn{6}{|l|}{ Obesity } \\
\hline Total effect (path $c$ ) & 0.082 & 0.009 & $<.001$ & - & - \\
\hline Direct effect (path $c^{\prime}$ ) & 0.080 & 0.009 & $<.001$ & - & - \\
\hline Indirect effect (via mediator) & 0.002 & 0.0009 & .013 & {$[0.0002 ; 0.004]$} & 0.028 \\
\hline \multicolumn{6}{|l|}{ BMI } \\
\hline Total effect (path $c$ ) & 0.005 & 0.0006 & $<.001$ & - & - \\
\hline Direct effect (path $c^{\prime}$ ) & 0.005 & 0.0006 & $<.001$ & - & - \\
\hline Indirect effect (via mediator) & 0.0001 & 0.00006 & .027 & {$[0.00002 ; 0.0003]$} & 0.027 \\
\hline \multicolumn{6}{|c|}{ Analyses are adjusted for age, sex, ethnicity, wealth, smoking status, hair treatment and depressive symptoms. } \\
\hline \multicolumn{6}{|c|}{$\begin{array}{l}* p \text { values shown for indirect effects are derived from the Sobel test for consistency with total and direct } \\
\text { effects, however bootstrap } 95 \% \text { confidence intervals provide a more robust indication of significant mediation } \\
\text { (see Method for more details). }\end{array}$} \\
\hline
\end{tabular}




\section{Figure legends}

Figure 1. Mediation model of associations between obesity and psychological wellbeing via perceived weight discrimination 